\title{
Chinese Realism Oil Painting's Thematic Evolution Since the Founding of New China
}

\author{
Xianjuan Dong \\ Department of Art and Design \\ College of Engineering and Technology \\ Chengdu University of Technology \\ Leshan, China 614000 \\ College of Art \\ Sichuan University \\ Chengdu, China 610065
}

\begin{abstract}
Considering fading of western modern art theme and withering away of painting, this paper reviews thematic development of oil-painting since the founding of new China. From the theme era when theme goes first to the 1980s with the universal theme of introspection on Cultural Revolution, resorting to violence and life of educated youth and to the post1990s when theme gradually fades, China's realism oil-painting's social function gradually fades. However, the author thinks that oil-painting's aesthetic function and social function cannot be neglected and they deserve attention from contemporary realist painters.
\end{abstract}

\section{Keywords—realism; oil painting; theme; evolution}

\section{INTRODUCTION}

Western modern art has evident "non-thematization" orientation. "Sacred theme" advocated by classical academism develops into realism school of painting with Courbet as its representative and starts to develop towards theme routinization. Then, it experiences impressionism, expressionism, cubism, abstractionism and zero painting with theme gradually fading and withering away. The theme I talk about refers to literature narrative carried by traditional painting and its social function of representing history or reality. Withering away of theme is also withering away of painting's social function. Painting no longer has the education functional view of "realization of education and improvement of human relations" (1). It becomes "purer and purer" visual art, which is the "pureness" pursued by modern art. Easel painting develops from dot, line and face without a theme or an image in abstractionism to "zero", namely blank. There is nothing to cast away. Then, painting itself suffers suspicion. In 1917, Du Shang names Pissoir as "Spring" and sends it to American independent salon for exhibition. Although it is not displayed, roughly an attitude is revealed: Du Shang thinks that painting works lose their existence value and ready-made article is artwork. The development of western modern art from pursuing "pureness" of art to abandoning easel painting is the inevitable result of infinite enlargement of painting's aesthetic function and total abandonment of social function. If the painting fails to consider the audience's understanding and acceptance degree and totally comes apart with reality, it definitely will die.

Looking back on development of China's modern oilpainting art, it has a history of about a hundred years. It becomes a kind of stereotyped political propaganda tool during the "Cultural Revolution" and experiences confusion and hesitation under the influence of western modern and postmodern trend of thought after 1980s. But, generally speaking, realism is still the mainstream of China's oil-painting. It is just that different themes of various periods interpret and understand realism in different ways. At the beginning of the founding of new China, since oil-painting's realistic language is close to real life and suitable for serving "politics, workers, peasants and soldiers", the government and relevant culture sectors are particular about it. Conforming to the need of the times, oil-painting with revolution and history theme gains prosperous development. "Three emphases" in Cultural Revolution period sings "hero odes" loudly in a stereotyped way. "Scar art" and "local art" which appear later make oilpainting's theme return to the "ordinary world". The "Stars art exhibition" and "85 fashion" at the beginning of 1980s start a tide of learning and imitating western modern art. Development history of various schools of western modern art is imitated and used by Chinese artists. "The new generation" artists of 1990s tend to describing little nothings of daily life, which can be called regression of realism. From hero odes to ordinary world and from fashion art to self regression, revolution of oil-painting's theme is also revolution of its social function. How to learn from favorable factors of western modern and post-modern art to make China's oil-painting continue to develop towards the road of realism? Is theme still a feature of China's modern realism oil-painting? What kind of social function does realism oil-painting carry in various periods of China? In order to answer these questions, we need to get on the spatial-temporal train and look back on revolution of oil-painting's theme since the founding of new China.

\section{THE ERA OF THEME (1949-1976)}

From the founding of new China to the end of "Cultural Revolution", China's oil-painting art learns and develops, and 
oil-painting art is greatly promoted by the government and relevant culture sectors due to the fact that its realistic language makes for "serving politics, workers, peasants and soldiers". Generally speaking, theme creation occupies the key position in this period. During the 10-year-long "Cultural Revolution", oil-painting becomes the slave of theme in the "theme first" task assignment creation. Just as one art theorist says: "In a long period of time, works' subject and theme get excessive attention. Works' idea and political appeal are emphasized repeatedly, whose excessive spreading does harm to development of art. Rejection towards and suppression on other artistic ideas, styles and schools lead to singleness and rigidness of realism art and realism art descends to being the tool of political fight in special years."(2) Although from the founding of new China to pre "Cultural Revolution" period and during the 10-year "Cultural Revolution", oil-painting art serves political propaganda. Due to differences in color and theme selection of oil-painting creation in those two periods, oil-painting shows different styles and features.

From the founding of new China to pre "Cultural Revolution" period, China's oil-painting art takes true-life realism style as the principal thing. For one thing, realistic oil painting is easy for the audience to understand and accept. For another thing, it is because of the need to reproduce the revolution history. At the beginning of the founding of new China, in order to eulogize and reproduce Chinese Communist Party's contribution to China's revolution and liberation in different historical periods, to sing the praises of revolutionary hero who sheds blood and lays down life and to erect a monument to and write a biography for significant historical events and turns of revolution, a batch of works reflecting revolutionary history is needed. Due to oil painting's scientific and rational creation features and realistic language style, it is more suitable to show this theme than Chinese painting. Thus oil painting of this theme obtains great development. Observing oil painting works in this period carefully, we can find that they are quite different from works of Cultural Revolution period in color, character expression and theme selection.

Firstly, in terms of color trend, oil painting of this period is greatly influenced by oil painting of the Soviet Union and the painting is usually shown in gray and other cold colors, which is relevant to the need to show revolutionary history and reflects artists' worship of "loftiness" at that time. A good example is Liu Hulan, created by Feng Fasi in 1957. Gloomy and cold sky in the painting shows villagers' sympathy towards Liu Hulan and hatred towards the executioner and adds atmosphere to Liu Hulan's inspiring awe by upholding justice and facing death unflinchingly. Compared with "red, bright and light" of "Cultural Revolution" period, works of this period are influenced little by set pattern and painters can decide the color according to needs of the painting.

In terms of character expression, since solemn and stirring, suffering, lofty and heroism are the emotional tone of works of this period, figures in the painting are mostly solemn and grave. For example, the expression of Chairman Mao in Chairman Mao in the Cave Dwelling (Xin Mang) and Comrade Mao Zedong in Jinggangshan (Luo Gongliu), two oil paintings with leadership theme, is dignified, stopping writing and thinking or gazing at the distance. The image of chairman here does not show the manner of "commenting on the affairs of state with a lot of emotion" described in the "Cultural Revolution" period. Instead, it shows a real and worried leader thinking about the future of revolution before us. The chairman here is an ordinary person who is close to us rather than the god in the "Cultural Revolution" period. In Join the Army, a painting of Wang Shikuo, although there are crowded people in the place to join the army and people have abnormal great passion for joining the army, character expression is real and natural rather than the same smile in the "Cultural Revolution" period.

In terms of theme selection, the main creation direction of this period is oil painting with the theme of reproducing significant revolution historical event and eulogizing revolutionary martyrs and leaders. Zhan Jianjun's Five Heroes on Langya Mountain is a representative of works with the theme of eulogizing revolutionary martyrs. The painter selects a well-known hero story and reproduces the scene of five heroes' glancing back before dying. The expression in their eyes is piercingly cold, solemn and grave, showing the soulstirring image of hero. There are many other paintings reproducing historical events, like Nanchang Uprising (Mo $\mathrm{Pu}$ ), China-Japan Yellow Sea Battle (Wu Shuyang), and Founding Ceremony (Dong Xiwen), and eulogizing leaders, like Chairman Mao in the Cave Dwelling (Xin Mang) and Chairman Mao at the December Meeting (Jin Shangyi). The Chinese Communist Party advocates "re-paraphrasing history with history" and historical painting is an important part of people's education in patriotism and shaping the image of new China, therefore historical painting develops rapidly in this period.

Leaving the period full of revolution historical painting and entering the fiery "Cultural Revolution" period, we can find that the previous grave and suffering theme is gradually abandoned and turns into a bright and optimistic direction, and revolution historical theme is gradually replaced by the theme reflecting real life. Works of this period are mainly about describing leaders' great image, eulogizing people's happy life and showing heroes in socialist construction with bright colors and grand vigor. Influenced by creation pattern of "socialism realism", almost all works are about positive praise. Under this circumstance, it is understandable that most oil painting works take "red, light and bright" as color motif.

In the Cultural Revolution period, most of the paintings with the theme of showing the great leadership image are portrayals of Mao Zedong. For example, Liu Chunhua's Chairman Mao Goes to Anyuan reproduces the scene that Mao Zedong goes to Anyuan to organize workers and go on strike in 1921. This oil painting is repeatedly printed and there are more than 0.9 billion copies. It becomes the creation template of leaders, just as model opera. Mao Zedong in the painting is straight and tall and mountains and the sea of clouds seem so small before him. Mao Zedong's expression is dignified with awe-inspiring righteousness, making the audience filled with deep esteem for the figure in the painting. In Tang Xiaohe's Marching against Strong Wind and Big Waves and Growing against Strong Wind and Big Waves, Mao Zedong is right in the middle of the painting and he is taller and more outstanding than people around. The paintings are warm-toned and people's 
face is thorough red, which is the typical style of that special time. As to works showing heroes in socialist construction, Pan Jiajun's I'm a "Petrel" is the representative. The heroine climbs onto the telegraph pole to make urgent repair on the cable in spite of rain. Her face gets red all over and tests telephone wire in mid air with high spirits, showing that females are as excellent as their male peers and showing revolutionary youth's socialist-minded and professional spirit.

Although oil painting of "Cultural Revolution" period uses realistic painting language, it has some stylization and stereotyped features, fully playing its social function of "serving the politics", advertising political ideas, implementing political tasks and rejecting any artistic tendency of antigovernmental will. Therefore, oil painting works of this period have relatively unified themes, acting as a tool of political propaganda to interpret official will.

\section{COMMON THEME (1977-1989)}

After Cultural Revolution, driven by scar literature, a batch of paintings reflecting on the Cultural Revolution and showing educated youth's "going and working in the countryside and mountainous areas" movement in China's oil painting field and they are collectively called "scar art". Oil painters, with $\mathrm{He}$ Duoling, Luo Zhongli and Cheng Conglin as representatives, create a batch of realism oil paintings with themes like Cultural Revolution, violent fighting and educated youth's life. Several examples are as follows: He Duoling's Spring Wind has Woken Up, Cheng Conglin's Snow in X of 1967 and Luo Zhongli's Father. Under this social background, people reflect a lot on the Cultural Revolution. Therefore, Mr. Fan Di says there is "common theme and universal care" in this period. The common theme actually is attention to products of special times, like Cultural Revolution and educated youth. With Luo Zhongli's Father as the mark, leading figure in oil painting turns from great men, leaders and historical figures to ordinary people. But oil painting of this period still carries strong social consciousness. Seeing from most of the works of this period, they fail to break through themes like Cultural Revolution, educated youth and native land. What artists care about are mainly social problems and they care little about ordinary people's real life and surviving experience.

Under the common theme, painting's social function is still stronger than its aesthetic function and oil painting still carries a certain literary narration and recording function. However, compared with the Cultural Revolution period, painting of this period no longer takes "red, light and bright" as the key color motif and the weakness of theme first and stereotyped creation is not so evident. Painters can relies on their own subjective emotion to draw what they think and how they feel. Undoubtedly, there is progressive significance here.

\section{INSIPID WITHERING OF THEME(POST-1990)}

Observing realism oil painting of the 1990s, we can find that oil painting art of this period no longer has the function of political interpretation as in the period of "Cultural Revolution" or bears the feature of "common theme and universal care"(Fan Di'an's saying) in the 1980s. The painting's form and language are enhanced to an unprecedented level. Due to the need of social function, theme creations eulogizing leaders of the Party Central Committee and unknown heroes and reproducing great historical events still exist. However, with changes of the times, "thematic creation" no longer unifies the whole country. Instead, it becomes one member of diversification. Painters of the new generation like to use daily life as their creation theme. Most of them are born after 1960 and they receive normal college education. Compared with painters of the previous generation, painters of the "new generation" no longer bear solemn social "mission sense" and they care about personal feelings. Therefore, they direct their personal view onto their familiar people and environment. Liu Xiaodong, Yu Hong, Wei Rong, Shen Ling and Chen Shuyuan are representatives of painters of the new generation. We seldom see creations reproducing the revolution or history in their paintings. Their paintings are descriptions of extremely trivial and ordinary daily life, like Liu Xiaodong's Father and Son and Idyllic Pastoral, Shen Ling's Rich Youth and Yu Hong's Witnessing Growth series. Their painting usually picks up a fragment of life to describe, but it is not reproduction of the objective reality. The painting aims to convey people's real living state in modern society. The new thing in creations of painters of the "new generation" is looking into ordinary people's ordinary life, which is a beneficial correction of the previous realism oil painting which only cares about heroes and grand historical events and neglects the worldly real life. It is also a response to the social need of art to reveal real features of the times.

Insipid withering of thematic painting in the 1990s is closely related to the influence of western modernism on China. Modernism pursues pureness of art and demands pure painting language. This kind of emphasis on painting itself decomposes the theme which is focused on by China's oil painting for a long time. The essence of decomposition of theme is dispelling oil painting's literary narrative, preach theme and "theme first". Painting's form and language defeats the reproduction theme and becomes the master of painting. Using Paul Klee's classic description of modern art, "Modern art is not about reproduction of the seen part, but about making the unseen part visible." (3) Then the new theme can be described as: "not reproduction of the theme, but making the unseen theme the theme". The unseen theme can be understood on two levels. First, the theme is not narration about or objective reproduction of historical events or real life literature. Second, the theme is artists' deep thought on reality and the external manifestation of their personal experience. The works truly reflect artists' emotion and personality and they reflect spirit of the time as well.

\section{CONCLUSION}

Actually, theme is a reflection on painting's social function. As the main functions of painting, both aesthetic function and social function can't be abandoned and we can't afford to abandon either of them. Since the founding of new China, between these two functions of oil painting, one wanes while the other one waxes, or one waxes while the other one wanes, which is the inevitable result of social development and is closely related to oil painting's development law. When modernism demands pure painting language and drives western painting deathward, Chinese oil painting still sustains its 
certain social function, which is worth celebrating. Nowadays, under the impact of post-modern ideological trend, we will wait and see how Chinese oil painting art continues to develop and gains transcendence over itself.

\section{REFERENCES}

[1] Zhang Yanyuan (Tang Dynasty), Notes of Past Famous Paintings[M]. Beijing: People's Fine Arts Publishing House. 2004.5. Page 1.

[2] Li Qun, Discussion on Art's Theme and Subject[J]. The Fine Arts. 1979.6. Page 15.

[3] Chen Zhongqiang, Using Rules Hidden in the Nature to Draw - Thought on Paul Klee's Notes on Literature and Art[J]. Journal of Xuehai. 2013.5. Page 213. 